\title{
A APLICAÇÃo DA FOTOQUíMICA INORGÂNICA NAS DIVERSAS ÁREAS DA CIÊNCIA
}

\author{
Rose Maria Carlos \\ Departamento de Química, Centro de Ciências Exatas e de Tecnologia, Universidade Federal de São Carlos, CP 676, \\ 13565-905 São Carlos - SP, Brasil
}

Recebido em 29/4/06; aceito em 29/1/07; publicado na web em 25/9/07

\begin{abstract}
APPLICATION OF INORGANIC PHOTOCHEMISTRY IN THE DIVERSE FIELDS OF SCIENCE. This article provides an overview of the current status of research involving the photochemical behavior of transition metal complexes in the following important areas: medicine, biology and materials science including some of the experiences of the writer. Coverage is selective, generally focusing on highlights and the most recent developments, with the broad aim of showing the interdisciplinary field of inorganic photochemistry.
\end{abstract}

Keywords: inorganic photochemistry; photochemical sensitization; photoredox reactions.

\section{INTRODUÇÃO}

O objetivo desta revisão é mostrar as diversas áreas de atuação da fotoquímica inorgânica. Pelo uso e discussão de trabalhos científicos esta revisão procura mostrar a conexão entre a fotoquímica inorgânica com os processos naturais e como esta conexão vem sendo direcionada para o desenvolvimento de processos artificiais. Para isso, a primeira parte desta revisão discute as diversas maneiras de obtenção de energia, seja elétrica ou química, bem como o transporte e armazenamento de energia. Na seqüência, esta revisão foi dividida em vários tópicos cobrindo várias áreas da ciência onde a fotoquímica inorgânica está presente com exemplos e discussões de trabalhos científicos nas áreas da biologia, medicina e materiais.

São mencionados vários artigos direcionados para simular e modelar os diferentes processos biológicos usando a luz e os complexos de metais de transição como modelos. Os efeitos benéficos e maléficos da luz sobre os receptores naturais presentes nos organismos vivos são apresentados com exemplos e citação de algumas enfermidades que podem ser tratadas com a luz.

A conexão entre processos naturais com os processos artificiais é demonstrada nos tópicos relacionados à aplicação das alterações conformacionais em várias moléculas induzidas pela luz e na formação de fios moleculares condutores. O uso da fotoquímica inorgânica na área ambiental é também discutido com trabalhos mostrando a degradação de polímeros pela luz.

\section{APLICAÇÕES DA FOTOQUÍMICA INORGÂNICA}

\section{Processos de conversão de energia solar em energia elétrica e química}

No final dos anos 80, as guerras entre os países produtores de petróleo e também a guerra fria entre EUA e Rússia deram margens para novas preocupações mundiais quanto à possibilidade de escassez do petróleo, que é nossa fonte principal de combustível. Outras fontes naturais, como o carvão, levam a preocupações quanto à escassez como também a problemas ambientais. Uma das alternativas viáveis é as usinas nucleares, que também apresentam restrições ambientais e políticas ${ }^{1}$. Em termos científicos, tais fatos

*e-mail: rosem@dq.ufscar.br resultaram em incentivos, por parte dos governos e das grandes empresas, com a finalidade de se estabelecer novas alternativas para a obtenção de energia elétrica e de combustíveis.

Uma estratégia muito estudada é a reação entre hidrogênio molecular e oxigênio, que gera água líquida e calor ${ }^{2,3}$.

$\mathrm{H}_{2}(\mathrm{~g})+\mathrm{O}_{2}(\mathrm{~g}) \rightarrow \mathrm{H}_{2} \mathrm{O}(\mathrm{l})-545 \mathrm{~kJ}$

Tal reação, por ser uma maneira limpa de obtenção de energia, levou ao estabelecimento de pesquisas denominadas como "Economia do Hidrogênio".

Dentro da fotoquímica inorgânica, vários cientistas direcionaram suas pesquisas para os métodos de conversão da energia solar em energia elétrica ou química ${ }^{4-9}$, o que é bastante razoável.

A maior parte da energia solar que chega à terra é dissipada na forma de calor. Esse processo é altamente eficiente

Luz $\rightarrow$ calor $100 \%$

Parte dela pode ser transformada em outras formas de energia, como química ou elétrica, ou pode ser usada para realizar algum tipo de trabalho mecânico. Entretanto, se a luz é transformada em calor e, depois, em eletricidade, o processo não apresenta mais $100 \%$ de eficiência.

A luz pode ser transformada diretamente em eletricidade usando-se as células fotovoltaicas ${ }^{4}$. Neste caso, a conversão da luz em eletricidade é obtida explorando-se os efeitos fotovoltaicos que existem nas junções de semicondutores ${ }^{5}$. O efeito fotovoltaico ocorre em materiais semicondutores, que se caracterizam pela presença de bandas de energia onde é permitida a presença de elétrons (banda de valência) e de outra vazia (banda de condução). O semicondutor mais usado é o silício.

Em uma célula fotovoltaica convencional, o semicondutor sólido, silício, deve realizar dois processos simultâneos: absorção da luz e separação das cargas (elétrons e buracos), os quais são produzidos pela absorção da luz .

Um dos problemas associados a essas células fotovoltaicas é que, para evitar a recombinação dos elétrons e buracos, o Si empregado deve ser de alta pureza e livre de defeitos, um processo de alto custo financeiro, o que restringe seu uso para a produção de eletricidade em escala industrial ${ }^{4}$. 
Uma alternativa ${ }^{5-7}$ para o silício é o óxido de titânio, $\mathrm{TiO}_{2}$. Este material semicondutor apresenta alta estabilidade térmica e fotoquímica, não é prejudicial ao meio ambiente, é encontrado em quantidades expressivas em rochas e tem produção anual da ordem de milhões de toneladas, sendo, desta forma, de baixo custo em relação ao silício. Entretanto, $\mathrm{TiO}_{2}$ não absorve luz visível uma vez que o intervalo de energia entre a banda de condução e a banda de valência é da ordem de $3 \mathrm{eV}$. Uma estratégia encontrada para superar esta barreira de energia é o uso de sensibilizadores fotoquímicos, moléculas que absorvam a luz e, no estado excitado, sejam capazes de transferir elétrons para o semi-condutor. Os dispositivos moleculares que operam com sensibilizadores fotoquímicos separam a função de absorção da luz (realizada pelo sensibilizador) do transporte de elétrons (realizada pelo semicondutor) (Figura 1).

Essas células solares usam corantes orgânicos e/ou complexos de metais de transição como sensibilizadores (espécies que absorvem luz) e iniciam o processo de transferência de elétrons para os filmes semicondutores ${ }^{6-8}$.

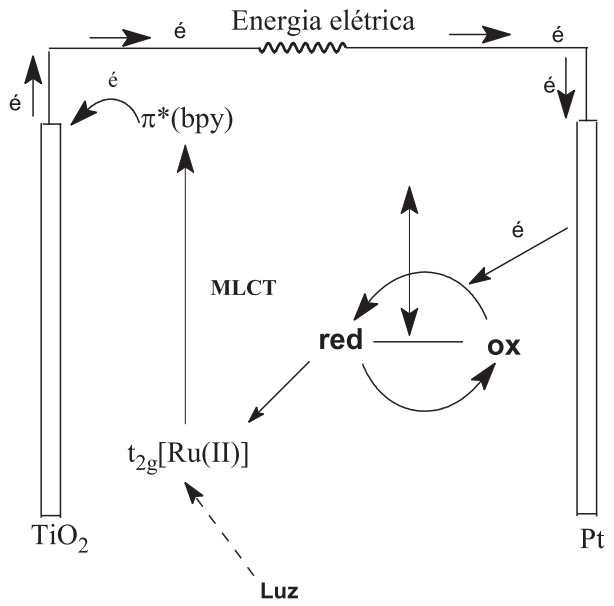

Figura 1. Uma célula fotovoltaica usando $\mathrm{TiO}_{2}$ como material semicondutor e um complexo polipiridínico de Ru(II) como espécie que absorve a luz. A irradiação com luz visível na banda de MLCT do complexo $\left(R u^{2+}, t 2 g \rightarrow b p y\right.$, $\left.\pi^{*}\right)$ induz o processo de transferência de elétrons no estado excitado do complexo para o semicondutor $\left(\mathrm{Ru}^{2+}, t 2 \mathrm{~g} \rightarrow\right.$ bpy, $\pi^{*} \rightarrow \mathrm{TiO}_{2}$ (banda de condução)

Em geral, nestes dispositivos moleculares o semicondutor fotossensibilizado $\left(\mathrm{TiO}_{2}\right)$ apóia-se em um eletrodo transparente, um eletrólito ativo-redox (geralmente o par $\left.\mathrm{I}_{3}^{-} / \mathrm{I}\right)$ e um contra-eletrodo (Figura 1). O sensibilizador absorve luz (cianometalato, complexo de Ru/polipiridina, corantes orgânicos etc) e injeta elétrons na banda de condução do semicondutor, Equações 3-6. A forma oxidada do sensibilizador é reduzida por um par redox presente na solução, geralmente um solvente orgânico contendo o par I-//_- O ciclo é completo após a redução do mediador redox no contraeletrodo. A voltagem gerada durante a iluminação corresponde à diferença entre o nível Fermi do eletrólito no estado sólido e o potencial redox do eletrólito.

$$
\begin{aligned}
& \mathrm{S} \stackrel{h v}{\rightarrow} \mathrm{S}^{*} \\
& \mathrm{~S}^{*}+\mathrm{TiO}_{2} \rightarrow \mathrm{e}^{-}\left(\mathrm{TiO}_{2}\right)+\mathrm{S}^{+} \\
& \mathrm{S}^{+}+3 / 2 \mathrm{I}^{-} \rightarrow \mathrm{S}+1 / 2 \mathrm{I}_{3}^{-} \\
& 1 / 2 \mathrm{I}_{3}^{-}+\mathrm{e}^{-}(\text {contra eletrodo }) \rightarrow 3 / 2 \mathrm{I}^{-}
\end{aligned}
$$

O sensibilizador ideal deve apresentar absorções na região do visível-infravermelho. Para uso em células fotovoltaicas, vários complexos derivados do $\left[\mathrm{Ru}(\mathrm{bpy})_{3}\right]^{2+}$ têm sido testados ${ }^{6-8}$. Em geral, eles apresentam grupos ancorados (grupos carboxílicos) para assegurar uma distribuição uniforme do sensibilizador sobre a superfície do óxido e para promover o acoplamento eletrônico dos níveis doadores do sensibilizador com os níveis do receptor (semicondutor).

Uma alternativa para os complexos de metais de transição é a sensibilização por extratos naturais de frutas, flores e folhas de plantas como os descritos na literatura ${ }^{7}$. Nestes experimentos obtiveram-se resultados superiores aos obtidos pelos processos tradicionais com complexos de $\mathrm{Ru}(\mathrm{II})$ e com custos menores.

Em geral, estas células fotovoltaicas podem ser operadas por cerca de 20 anos consecutivos com ganho energético da ordem de $10-15 \%$, o que viabiliza sua fabricação em escala industrial. Uma das desvantagens é a grande área superficial necessária para sua instalação e a necessidade de luz solar a maior parte do tempo.

Um aspecto importante que deve ser considerado no aproveitamento da energia solar é que a eletricidade só pode ser estocada se for transformada em alguma outra forma útil de energia, como em energia química obtida nas baterias recarregáveis. Outra questão a ser discutida é que precisamos de combustível para movimentar carros, trens, motores e também gerar eletricidade. Só que esse tipo de combustível não é reciclado, ele é liberado como gases de exaustão e calor. Assim, o material de partida deve ser limpo para preparar o combustível, pronto para uso e abundante. O candidato ideal é a água.

Uma alternativa é produzir energia elétrica e, então, estocar por exemplo, na forma da mistura $\mathrm{H}_{2}(\mathrm{~g})$ e $\mathrm{O}_{2}(\mathrm{~g})$, que pode ser obtida diretamente pela eletrólise da água. $\mathrm{O}$ rendimento dessa transformação é de $70 \%$, mas inviável uma vez que requer o consumo de grandes quantidades de energia elétrica, não sendo economicamente competitivo em comparação ao petróleo ${ }^{2}$. Além disso, para oxidar a água a potenciais relativamente baixos, sem a formação de intermediários de alta energia, são necessários 4 elétrons para que o processo ocorra em uma única etapa ${ }^{9,10}$ :

$2 \mathrm{H}_{2} \mathrm{O} \rightarrow 4 \mathrm{e}^{-}+4 \mathrm{H}^{+}+\mathrm{O}_{2} \quad\left(\mathrm{E}^{0}=0,82 \mathrm{~V}\right.$ vs $\mathrm{NHE}$ a pH 7$)$

Este é um processo endergônico.

$1 / 2 \mathrm{H}_{2} \mathrm{O} \rightarrow 1 / 2 \mathrm{H}_{2}(\mathrm{~g})+1 / 4 \mathrm{O}_{2}(\mathrm{~g}) \Delta \mathrm{G}=1,23 \mathrm{eV}$

Tal reação poderia ser viabilizada fotoquimicamente, mas a água é transparente na região do visível. Nestes casos, a estratégia usada é induzir a reação usando um sensibilizador fotoquímico, por exemplo, o complexo $\left[\mathrm{Ru}(\mathrm{bpy})_{3}\right]^{2+}$.

Neste processo, a absorção de luz visível pelo sensibilizador $\left[\mathrm{Ru}(\mathrm{bpy})_{3}\right]^{2+}$ leva à formação do complexo excitado, o que, então, reduz a $\mathrm{H}_{2} \mathrm{O}$ produzindo $\mathrm{H}_{2}$ molecular. $\mathrm{O}$ sensibilizador é regenerado pela oxidação da água, produzindo oxigênio molecular ${ }^{10}$.

Fotoquímica

$\left[\mathrm{Ru}(\mathrm{bpy})_{3}\right]^{2+} \stackrel{h v}{\longrightarrow} *\left\{\left[\mathrm{Ru}(\mathrm{bpy})_{3}\right]^{2+}\right\} \quad \Delta \mathrm{G}=+2,12 \mathrm{eV}$

Célula combustivel

$*\left\{\left[\mathrm{Ru}(\text { bpy })_{3}{ }^{2+}\right\}+\mathrm{H}^{+} \rightarrow\left[\mathrm{Ru}(\text { bpy })_{3}\right]^{3+}+1 / 2 \mathrm{H}_{2} \quad \Delta \mathrm{G}=-0,44 \mathrm{eV}\right.$

$\left[\mathrm{Ru}(\text { bpy })_{3}\right]^{3+}+1 / 2 \mathrm{H}_{2} \mathrm{O} \rightarrow\left[\mathrm{Ru}(\text { bpy })_{3}\right]^{2+}+\mathrm{H}^{+}+1 / 4 \mathrm{O}_{2} \Delta \mathrm{G}=-0,45 \mathrm{eV}$

Esses sistemas são capazes de repetidas seqüências na mesma solução sem perda apreciável de sinal, até que a maior parte do redutor seja consumido. Na prática, as etapas são lentas por razões cinéticas devido à natureza multieletrônica do processo de quebra da $\mathrm{H}_{2} \mathrm{O}$, assim, essas reações só ocorrem de maneira eficiente na 
presença de receptores de elétrons e de catalisadores ${ }^{10}$.

A fotoquímica com o uso de sensibilizadores oferece uma alternativa atrativa para viabilizar processos de conversão de energia solar em elétrica e química. Entretanto, é importante salientar que sistemas dependentes dessa estratégia fotossensibilizador-rastreador produzem perda de espécies devido à decomposição da espécie rastreadora de elétrons ${ }^{10}$. Neste sentido, é fundamental a pesquisa por dispositivos moleculares eficientes com base em reações fotoquímicas limpas que usem somente luz como fornecedor de energia.

Aqui é importante salientar que os processos de conversão de energia solar em energia elétrica podem ser considerados modelos biomiméticos da fotossíntese ${ }^{11}$, Equações 12-14, porque usam a energia transferida pelo fotossensibilizador para gerar um estado excitado com separação de cargas $\left\{\mathrm{M}^{+/-}-\mathrm{L}^{-/+}\right\}$(semicondutor) e neste estado excitado transferem a energia para a molécula receptora (carregador externo). Neste contexto, fazendo um paralelo entre a eficiência e o mecanismo da reação, podemos afirmar que, comparada à fotossíntese, as duas reações fotoquímicas operando em série permitem a utilização total da parte ativa fotoquimicamente do espectro solar. Também, considerando-se que a estocagem de energia na fotossíntese apresente eficiência ao redor de $10 \%$ nos processos artificiais, tem se alcançado a ordem de $15 \%$, o que motiva as pesquisas nesta área ${ }^{11}$.

$6 \mathrm{H}_{2} \mathrm{O}+6 \mathrm{CO}_{2} \stackrel{\text { luz }}{\longrightarrow} \mathrm{C}_{6} \mathrm{H}_{12} \mathrm{O}_{6}+6 \mathrm{O}_{2}$

$2 \mathrm{H}_{2} \mathrm{O} \stackrel{\text { luz }}{\longrightarrow} 2 \mathrm{H}_{2}+\mathrm{O}_{2}$

$2 \mathrm{H}_{2} \mathrm{O}+2 \mathrm{CO}_{2} \stackrel{\text { luz }}{\longrightarrow} 2 \mathrm{HCOOH}+\mathrm{O}_{2}$

Transferência de elétrons em sistemas biológicos - simulando o processo de transferência de elétrons em metaloproteínas

As reações de transferência de elétrons são etapas-chaves em muitos processos biológicos, tais como fotossíntese, fosforilação oxidativa, metabolismo e fixação do nitrogênio ${ }^{12}$. Entender a função dos peptídeos e proteínas em intermediar as reações de transferência de elétrons a distâncias longas tem implicações físicas, químicas e biológicas fundamentais ${ }^{13}$. Por ex., radicais de aminoácidos aromáticos são intermediários-chaves na biossíntese do ácido nucléico, reparo do DNA, redução do dioxigênio pela citocromo oxidase, oxidação da água pelo PSII, assim como outros processos biológicos ${ }^{14}$. Essas reações ocorrem entre centros redox ativos (cofatores orgânicos ou complexos metálicos) unidos por interações físicas intermoleculares dentro das matrizes proteicas ${ }^{14}$. Em muitos casos, o contato direto entre o par redox é dificultado pelo enovelamento da proteína. Neste caso, a transferência de elétrons ocorre através da matriz polipeptídica uma vez que o par redox está separado por mais de $10 \AA$ A. Apesar da distância não colisional que o elétron deve atravessar, esta reação é extremamente rápida e procede com alta especificidade ${ }^{14}$.

A natureza apresenta caminhos eficientes de controle das reações de transferência de elétrons, tanto de maneira espacial como temporal. Um dos mecanismos de controle é colocar os centros redox na ordem de seus potenciais de redução, de forma que a força motriz da reação seja sempre decrescente em energia livre. Isto é essencial para que a mudança de energia livre total seja eficientemente convertida em trabalho sem ser dissipada em calor. Este cenário é evidente tanto na cadeia respiratória observada na mitocôndria como na fotossíntese. Na mitocôndria ${ }^{15}$ (Figura 2), os elétrons são transferidos da nicotinamina adenina dinucleotídeo (NADH) ou flavina adenina dinucleotídeo $\left(\mathrm{FADH}_{2}\right)$ para o oxigê- nio molecular $\left(\mathrm{O}_{2}\right)$ por uma série de reações envolvendo sempre dois centros redox que se encontram por colisões difusionais (citocromoC - citocromoC oxidase; citocromoC redutase citocromoC). Para essas reações, a direção do fluxo de elétrons é determinada pela especificidade da interação entre os pares redox ${ }^{15}$.

A complementaridade entre as superfícies das proteínas em termos de contornos e cargas fornece uma probabilidade maior de transferência de elétrons que aquela que surge de colisões randônicas ${ }^{15}$. Essa seqüência de reações resulta em um deslocamento de energia livre total de $1,4 \mathrm{~V}$ (53 Kcal), que é utilizado na síntese do ATP ${ }^{15}$.

Resumindo, a combinação de sintonia da força motora da reação, os acoplamentos a longa distância entre o sítio doador (D) e o sítio receptor $(\mathbf{R})$ e os fatores que governam o reconhecimento molecular asseguram que uma "reação ocorra no momento e lugar certos"15.

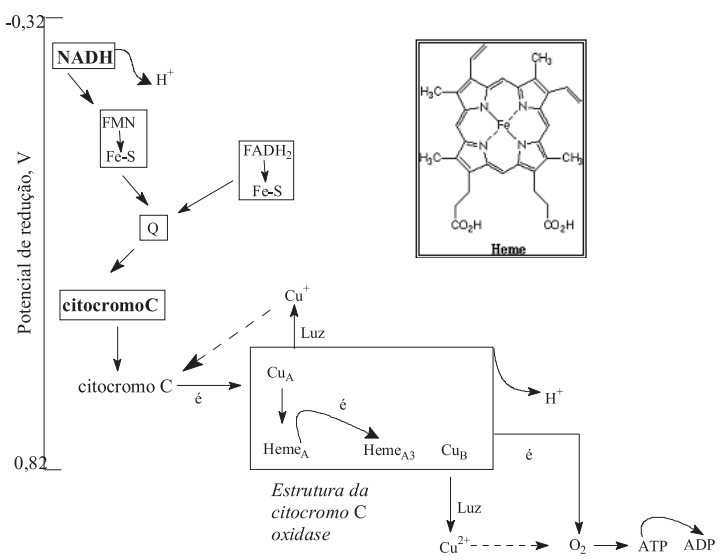

Figura 2. Representação das reações de transferência de elétrons na cadeia respiratória da mitocôndria. $\mathrm{NADH}=$ nicotinamida adenina dinucleotídeo reduzida $; \mathrm{FADH}_{2}=$ flavina adenina dinucleotídeo reduzida $; \mathrm{FMN}=$ flavina mononucleotídeo; $\mathrm{Fe}-\mathrm{S}=$ proteínas ferro-enxofre; $Q=$ ubiquinona. $A$ absorção de luz visível pelo citocromo $C$ oxidase pode desencadear dois processos redox, que resultam na inibição ou no aumento da produção do $A D P$ a partir do ATP

A elucidação dos aspectos físicos e químicos desses fenômenos requer aproximações tanto teóricas como experimentais. Por isso, as propriedades químicas e físicas dessas reações em meio biológico têm fascinado igualmente cientistas teóricos e experimentais, não sendo surpreendente que o entendimento desses processos tenha avançado rapidamente nas ultimas décadas ${ }^{16}$.

A fotoquímica inorgânica apresenta várias vantagens para o estudo desses processos rápidos, como resolução temporal e seletividade. Várias estratégias têm sido propostas, que vão desde a modificação das proteínas por complexos metálicos até a substituição de metais na estrutura proteica ${ }^{17}$.

Uma das alternativas propostas para o estudo das reações de transferência de elétrons meio proteico foi fornecida por Gray e colaboradores em 1982, usando o método conhecido como "flash/quench"18. Por esse método, investigaram-se as reações de transferência de elétrons ${ }^{19,20}$ de duas proteínas de $\mathrm{Cu}(\mathrm{II})$, que apresentam estruturas já caracterizadas, $\mathrm{Cu}(\mathrm{II})$-His107 e $\mathrm{Cu}(\mathrm{II})$-His83 modificadas pelo complexo de $\operatorname{Re}(\mathrm{I}),\left[\operatorname{Re}(\mathrm{CO})_{3}(\mathrm{fen})\left(\mathrm{H}_{2} \mathrm{O}\right)\right]^{+}$. Os resultados teóricos e experimentais sobre a His107 mostram que a oxidação do centro de $\mathrm{Cu}^{+}$ocorre via transferência de elétrons pelo grupo tirosina108

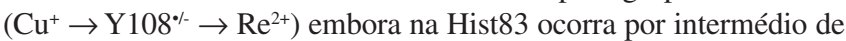
um grupo triptofano, W48. As espécies radicalares foram detectadas pela técnica de RPE.

O interessante nesse sistema foi a observação de que W48*(His83) não oxida Y108(H83) na escala de tempo do experimento de RPE. Os autores propõem que W48 é o produto termodinamicamente es- 
tável da oxidação do complexo $[\mathrm{Re}(\mathrm{His} 83)]^{+} \mathrm{AzM}^{2+}$. Isto significa que a ordem de redução esperada ${ }^{11}, \mathrm{~W} / \mathrm{W}>\mathrm{Y} / \mathrm{Y}$ em solução aquosa (pH 7,4), é invertida neste complexo.

O processo global é representado pelas Equações 15 e 16:

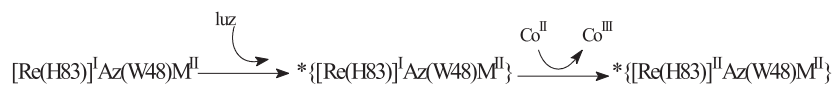

$$
[\operatorname{Re}(\mathrm{H} 83)]^{\mathrm{I}} \mathrm{Az}\left(\mathrm{W} 48^{0}\right) \mathrm{M}^{\mathrm{II}} \underset{\widehat{r}_{-\mathrm{H}^{+}}}{ } *\left\{[\operatorname{Re}(\mathrm{H} 83)]^{\mathrm{I}} \mathrm{Az}\left(\mathrm{W} 48^{0 \dagger}\right) \mathrm{M}^{\mathrm{II}}\right\}
$$

Uma outra estratégia proposta envolve a ligação de um foto sensibilizador a uma metaloproteína via um espaçador alifático coordenado ao sítio ativo da enzima ${ }^{21}$ (Equações 17-19).

Neste sistema, o estado excitado do complexo $\left[\mathrm{Ru}(\mathrm{bpy})_{3}\right]^{2+}$ é suprimido oxidativamente por $\left[\mathrm{Co}\left(\mathrm{NH}_{3}\right)_{5} \mathrm{Cl}\right]^{2+}$ produzindo $\left[\mathrm{Ru}(\mathrm{bpy})_{3}\right]^{3+}$, o qual retira um elétron do anel da porfirina. A reação de transferência de elétrons é seguida pela oxidação do Fe(III) pelo radical porfirínico formado ${ }^{21}$. Tal estratégia é particularmente interessante quando o centro redox ativo é muito protegido pelo meio proteico, de forma que a reação de transferência de elétrons entre o sítio ativo da proteína e seu agente redox externo se torna ineficiente.

$$
\begin{aligned}
& \mathrm{Ru}^{\mathrm{II}}(\text { bpy })_{3} m(\text { heme }) \mathrm{Fe}^{\mathrm{III}} \longrightarrow{ }^{*} \mathrm{Ru}^{\mathrm{II}}(\mathrm{bpy})_{3} m(\text { heme }) \mathrm{Fe}^{\mathrm{III}} \\
& { }^{*} \mathrm{Ru}^{\mathrm{II}}(\mathrm{bpy})_{3} m(\text { heme }) \mathrm{Fe}^{\mathrm{III}} \stackrel{\left[\mathrm{Co}\left(\mathrm{NH}_{3}\right)_{5} \mathrm{Cl}\right]^{2+}}{\longrightarrow} \mathrm{Ru}^{\mathrm{III}}(\text { bpy })_{3} \cdots(\text { heme }) \mathrm{Fe}^{\mathrm{III}}(1 \\
& \mathrm{Ru}^{\mathrm{II}}(\text { bpy })_{3} w(\text { heme })^{+} \cdot \mathrm{Fe}^{\mathrm{III}} \longrightarrow \mathrm{Ru}^{\mathrm{II}}(\text { bpy })_{3} w(\text { heme }) \mathrm{Fe}^{\mathrm{IV}}
\end{aligned}
$$

\section{Fotoquímica aplicada à medicina - terapia fotoredox}

As pesquisas na área de química medicinal estão voltadas a questões como resistência a drogas, toxicidade e alternativas para melhorar o alcance dos alvos de interesse $\mathrm{e}^{22}$. A esse respeito, a fotoquímica oferece a possibilidade de iniciar a ação desejada, no local de interesse. Com esse intuito surgiu a fototerapia, que pode ser definida pelo uso da luz visível ou próxima ao visível como agente terapêutico em clínica médica.

Para ser efetiva, a luz deve penetrar e se propagar no tecido da maneira mais eficiente possível. Ambos os processos dependem tanto das características de absorção do tecido como das propriedades da luz. A propagação depende da presença de regiões nãohomogêneas, como membranas, núcleos, água ou corantes, que absorvem muita luz, como a melanina e as porfirinas. A fototerapia usa luz compreendida na região de $620-850 \mathrm{~nm}$, onde se observa maior permeabilidade pela pele; por isso, esta região é denominada janela fototerapêutica ${ }^{23}$. Por ex., a região compreendida entre 600-700 nm, constituída principalmente por grupos porfirínicos, tem maior efeito de penetração ( $>50 \%$ ) que, por exemplo, a luz de 400-500 nm constituída por grupos flavinas, colágeno, NADH, nicotinamida.

Hoje em dia, encontramos várias fontes de luz artificial. A escolha depende da localização da lesão, da região espectral de interesse e da dose de luz a ser entregue. As fontes de luz mais comuns incluem os lasers de $\mathrm{Ar}, \mathrm{Kr}$ e $\mathrm{He} / \mathrm{Ne}$ (colimadas e monocromáticas) e as lâmpadas de arcos de xenônio (não colimadas). Uma vez que as lâmpadas não podem ser acopladas a fibras óticas, elas são restritas a tratamentos de lesões na pele, enquanto o laser é usado para tratamentos endoscópicos ${ }^{23}$.

Uma reação fotobiológica envolve a absorção da luz de com- primento de onda específico por uma molécula receptora. Este tipo de reação é bem conhecido dos organismos vivos, onde encontramos moléculas fotorreceptoras naturais como a rodopsina (responsável pela visão) ${ }^{24}$ e a clorofila (fotossíntese) ${ }^{25}$.

A visão, por exemplo, inicia quando a luz é focalizada na retina, camada de células que recobre o interior do globo ocular. A retina contém células fotorreceptoras conhecidas como bastonetes e cones. A rodopsina, localizada nas partes superiores dos bastonetes e cones, consiste em uma proteína, chamada opsina, ligada a um pigmento violeta avermelhado chamado retinal. As variações estruturais ao redor de uma ligação dupla na porção retinal da molécula iniciam uma série de reações químicas que resultam na visão. A visão depende da rigidez das ligações duplas no retinal. Em sua forma normal, o retinal é mantido rígido por suas ligações duplas, como mostra a Figura 3. A luz visível, incidindo no olho, é absorvida pela rodopsina e a energia é usada para quebrar a ligação $\pi$ da ligação dupla, indicada na Equação 20. A molécula gira ao redor dessa ligação, mudando sua geometria. O retinal separa-se da opsina, iniciando uma série de reações que produzem um impulso nervoso, que o cérebro interpreta como a sensação de visão. $\mathrm{O}$ retinal reverte-se lentamente à sua forma original e religa-se à opsina. A lentidão desse processo ajuda a explicar porque a luz intensa causa cegueira temporária. A luz faz com que todo o retinal se separe da opsina, não deixando nenhuma outra molécula absorver a luz.

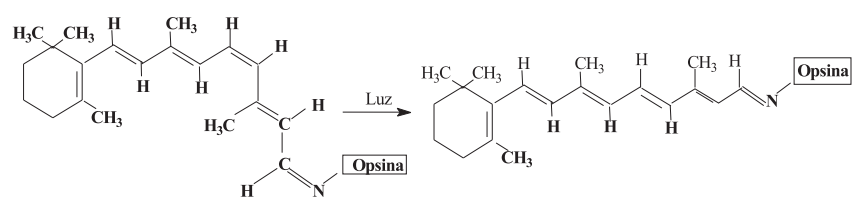

Figura 3. Representação de uma molécula de rodopsina mostrando que a absorção da luz visível leva à modificação conformacional da molécula, desencadeando uma série de processos bioquímicos que geram impulsos nervosos, traduzidos pelo cérebro na forma de imagens

A fototerapia combina luz com uma molécula receptora não especializada (moléculas que podem absorver luz de determinados comprimentos de onda, mas que não são órgãos receptores de luz especializados). Ela é dividida em duas categorias ${ }^{26}$ : fototerapia direta (sem administração de um sensibilizador) e fototerapia indireta (com administração de um sensibilizador).

$\mathrm{Na}$ fototerapia direta a absorção de luz por uma molécula endógena (natural), como proteínas ou ácidos nucléicos, pode conduzir a reações bioquímicas específicas ou pode afetar todo o metabolismo celular ${ }^{27}$.

$\mathrm{O}$ uso direto da luz como agente terapêutico é importante nos casos de deficiência da vitamina $\mathrm{D}$, icterícia, depressão ${ }^{27}$ etc. Por ex., a icterícia ${ }^{27}$ ocorre em recém-nascidos que apresentam um excesso do pigmento bilirrubina no sangue e tecidos. Esse pigmento é um produto do catabolismo da hemoglobina. Uma vez produzido, é transformado, por uma série de reações enzimáticas, em uma espécie conjugada mais solúvel, que é eliminada pelo organismo. Tanto a insuficiência na atividade enzimática como o excesso na quebra da hemoglobina no organismo podem resultar no acúmulo de bilirrubina e acarretar surdez e danos ao sistema nervoso central. Visualmente, esse distúrbio pode ser detectado pela coloração amarelada do bebê. $\mathrm{O}$ tratamento mais comum para tal desordem no organismo é a incidência de luz diretamente sobre a pele do bebê, o que promove a decomposição fotoquímica deste pigmento, facilitando sua liberação pelo organismo. 
A irradiação com luz visível pode também ter um efeito bioestimulante, que ocorre quando a luz promove uma alteração na cadeia redox da mitocôndria. Esse processo pode levar tanto à vasodilatação como à vasoconstrição. Isto ocorre porque muitas das proteínas que participam da cadeia respiratória podem também atuar como receptores de $l u z^{28}$.

O processo pode ser observado na citocromoC-oxidase, que é uma enzima terminal da cadeia respiratória. Esta enzima apresenta grande complexidade estrutural consistindo de dois núcleos heme (heme ${ }_{A}$ e heme $e_{B}$, dois sítios redox ativos de cobre $\left(\mathrm{Cu}_{\mathrm{A}}\right.$ e $\left.\mathrm{Cu}_{\mathrm{B}}\right)$, um de $\mathrm{Zn}$ e um de $\mathrm{Mg}$, podendo todos absorver luz (Figura 2).

$\mathrm{O}$ centro de $\mathrm{Cu}(\mathrm{II})$ apresenta uma série de absorções intensas ${ }^{29}$ atribuídas a transições de transferência de carga ligante-metal: $\left(\mathrm{N}_{\text {imidazol }} \rightarrow \mathrm{Cu}\right)$ na região de $400-450 \mathrm{~nm},\left(\mathrm{~S}_{\text {cisteina }} \rightarrow \mathrm{Cu}\right)$ a $680 \mathrm{~nm}$ e $\mathrm{S}_{\text {metionina }} \rightarrow \mathrm{Cu}$ a $620 \mathrm{~nm}$. De maneira geral, a citocromoC-oxidase pode ser totalmente oxidada (4 centros metálicos ativos redox: $\mathrm{Cu}_{A}$, $\mathrm{Cu}_{\mathrm{B}}$ no estado de oxidação $2+, \mathrm{Fe}_{\mathrm{A}}$ e $\mathrm{Fe}_{\mathrm{A} 3}$ com número de oxidação $3+$ ) ou totalmente reduzidos (4 centros metálicos com número de oxidação 2+ para $\mathrm{Fe}$ e 1+ para $\mathrm{Cu}$ ).

A excitação de células mitocondriais nas bandas de LMCT pode tanto acelerar o metabolismo celular como inibir. Por exemplo, irradiação com luz de $680 \mathrm{~nm}\left(\mathrm{~S}_{\text {cisteina }} \rightarrow \mathrm{Cu}\right)$ leva a um aumento da concentração de íons $\mathrm{Cu}_{\mathrm{B}}$ (oxidado) deslocando o equilíbrio em direção à fosforilação oxidativa (Figura 2). Este movimento tem como conseqüência o enovelamento da proteína, a síntese do DNA, RNA e o aumento da divisão celular, melhorando a circulação sangüínea (aumenta a vasodilatação). Por outro lado, luz de 725 $\mathrm{nm}\left(\mathrm{Cu}_{\mathrm{A}}\right.$ reduzido) inibe a fosforilação oxidativa, favorecendo a vasoconstrição. A irradiação com luz monocromática altera a razão das formas reduzida e oxidada da enzima e, conseqüentemente, a resposta biológica da célula. Esses efeitos são amplamente usados na área médica.

A fototerapia indireta é um tratamento médico que emprega a combinação da luz e uma droga para obter um efeito citotóxico ou alterar um efeito não desejado (câncer) em um tecido ${ }^{30}$. Para que isso ocorra, a droga ou fotossensibilizador que é administrado ao paciente deve apresentar toxicidade negligenciável no escuro e ser preferencialmente acumulada nas células doentes. Quando a concentração da droga nas células doentes é maior que a observada para as células saudáveis (observado pela incidência de luz UV quando o sensibilizador é uma droga luminescente, porfirinas, complexos de metais de transição), inicia-se a incidência de luz em doses controladas até a necrose do tecido doente ou até que este tecido seja convenientemente modificado. A quantidade de luz para promover a necrose do tecido deve ser controlada, de forma a não atingir as células saudáveis. A droga fotossensibilizada pode transferir parte da sua energia de excitação para o oxigênio molecular (tripleto) gerando o oxigênio singleto (extremamente reativo). $\mathrm{Na}$ terapia fototérmica, o sensibilizador excitado retorna ao estado fundamental liberando seu excesso de energia de excitação na forma de calor. Este efeito térmico pode induzir danos localizados e irreversíveis ao tecido doente e, desta forma, promover a necrose celular. Como resultado, observa-se uma série de reações químicas ao redor do tecido promovendo a apoptose celular.

Em geral, os estudos relacionados com a geração fotoquímica do oxigênio singleto para aplicação em terapia fotodinâmica (PDT) ainda são restritos às porfirinas, fitalocianinas e seus compostos metaloderivados, apesar de muitos complexos de rutênio(II) também serem capazes de produzir esta espécie altamente reativa ${ }^{31}$. Para esses compostos, os valores de rendimento quântico para a geração do oxigênio singleto são dependentes do complexo e do solvente, variando de $0,19\left(\left[\mathrm{Ru}\left(2,5^{\prime} \text {-bipiridina }\right)_{3}\right]^{2+}\right.$ em $\left.\mathrm{D}_{2} \mathrm{O}\right)$ para $1,0\left(\left[\mathrm{Ru}\left(5,5^{\prime}-\mathrm{SO}_{3} \mathrm{H} \text {-fenantrolina }\right)_{3}\right]^{2+} \mathrm{em} \mathrm{CD} \mathrm{CD}_{3} \mathrm{OD}\right)$. Os complexos

de $\mathrm{Ru}(\mathrm{II})$ polipiridínicos podem também apresentar desativação não-radiativa dos estados excitados de MLCT e, desta forma, podem atuar em terapia fototérmica. Em adição, os complexos polipiridínicos de $\mathrm{Ru}(\mathrm{II})$ podem penetrar na membrana celular, o que representa uma grande vantagem para a aplicação destes compostos em clínica médica ${ }^{31}$.

Uma outra estratégia empregada em clínica médica é a combinação da quimioterapia com a PDT, o que leva a um efeito antitumoral expressivo $^{32}$. Um sistema bem estudado envolve porfirinas ligadas a sítios laterais de complexos cis-[ $\left.\mathrm{Pt}\left(\mathrm{NH}_{3}\right)_{2}(\mathrm{Cl})_{2}\right]$ e cis-carboxi-platina, que são consideradas drogas antitumorais "clássicas". A solubilidade, reatividade e seletividade destes complexos podem ser moduladas alterando-se a primeira esfera de coordenação da Pt(II) ou os substituintes periféricos, tanto na porfirina como nos ligantes quelantes. A porfirina absorve a luz incidente levando à excitação dos complexos, que então podem atuar como agentes quimioterapêuticos e fotodinâmicos ao mesmo tempo. A atividade antitumoral desses complexos foi testada em células tumorais ${ }^{32}$.

Uma outra combinação de metalodrogas com fotossensibilizadores polipirrólicos foi descrita recentemente por Ford e colaboradores ${ }^{32}$. Clusters nitrosilos de $\mathrm{Fe}-\mathrm{S}$, atuando como doadores de NO, foram ligados covalentemente ao fotossensibilizador protoporfirina. Neste estudo, a excitação com luz visível na porfirina promoveu a liberação do NO, por um processo de transferência de energia eletrônica para o centro de Fe-S.

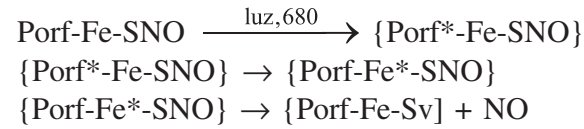

Compostos doadores de NO abrem novas fronteiras para fármacos ativados via processos fotoquímicos ${ }^{33}$. O fármaco pode se ligar covalentemente a um metal de transição formando um composto estável termicamente. Após ser administrado no paciente, o fármaco pode ser deslocado do complexo no local desejado, de forma controlada, por irradiação local usando-se um laser e fibras óticas. A molécula carregadora (complexo de metal de transição) deve ser de fácil preparação, ter toxicidade mínima no escuro e apresentar reatividade fotoquímica que leve ao deslocamento do fármaco na forma apropriada, gerar somente um produto não tóxico e facilmente excretado pelo organismo. Nestes casos, o complexo de metal de transição pode tanto atuar como uma molécula carregadora de fármaco, liberando a droga por um processo de substituição fotoquímica, Equação 23, como pode atuar como uma pródroga, Equação 24. Neste último caso a droga é gerada por um processo fotoquímico, geralmente redox entre o centro metálico e um ligante precursor do fármaco.

$\mathrm{M}-$ droga $\stackrel{\operatorname{luz}}{\longrightarrow}\{\mathrm{M}-\text { droga }\}^{*} \rightarrow \mathrm{M}-\mathrm{Sv}+$ droga
$\mathrm{M}-\mathrm{L} \stackrel{\operatorname{luz}}{\longrightarrow}\left\{\mathrm{M}^{+/-}-\mathrm{L}^{-/+}\right\} \rightarrow \mathrm{M}^{+/-}-\mathrm{Sv}+$ droga

No meio biológico, o deslocamento de óxido nítrico de drogas doadoras de NO pode proceder por caminhos espontâneos ou catalisados por enzimas ${ }^{34}$. Nos mamíferos, existem pelo menos 3 tipos de NOS: neuronal (nNOS), endotélico (eNOS) e induzível (iNOS). Devido à função sinalizadora do $\mathrm{NO}^{0}$ em muitos processos biológicos, o descontrole da sua concentração no organismo acarreta uma série de doenças ${ }^{35}$. Especificamente, a superprodução de $\mathrm{NO}^{0}$ por iNOS está envolvida diretamente nas patologias inflamatórias, como artrite reumatóide, choque septo, arteriosclerose e diabetes ${ }^{35}$. Por outro lado, a falta de $\mathrm{NO}^{0}$ no organismo pode acarretar problemas cardiovasculares, como descontrole na pressão sangüínea e ataques do coração. 
Esses efeitos maléficos motivaram pesquisas por compostos doadores ou seqüestradores de $\mathrm{NO}^{0}$ no organismo humano ${ }^{36}$. Entre os vários doadores de $\mathrm{NO}^{0}$ pesquisados até o momento, somente o complexo $\mathrm{Na}_{2}\left[\mathrm{Fe}(\mathrm{CN})_{5}(\mathrm{NO})\right]$ é usado na clínica médica. Este composto, que atua no controle de crises de hipertensão, é aplicado no paciente somente nos centros de terapia intensiva ${ }^{36}$, quando outras drogas não surtem mais efeito. Apesar do nitroprussiato ser uma droga viável e eficiente, existem certas reservas ao seu uso, uma vez que se acredita que ele é metabolizado nas células vermelhas com um deslocamento rápido de cianeto na corrente sangüínea ${ }^{37}$. Em adição, estudos fotoquímicos mostraram que a luz também é responsável pelo deslocamento do cianeto ${ }^{37}$. A administração simultânea de vitamina B12 impede o envenenamento ${ }^{37}$ por $\mathrm{CN}^{-}$.

Os complexos de $\mathrm{Ru}(\mathrm{II})$ são candidatos particularmente interessantes como substitutos ao nitroprussiato de sódio, dada a sua baixa toxicidade comprovada ${ }^{38-40}$.

Para que compostos do tipo $\mathrm{Ru}^{\mathrm{II}}-\mathrm{NO}^{+}$atuem como pró-drogas espera-se que o centro metálico se comporte como agente redutor reduzindo o ligante nitrosilo (um receptor $\pi$ - forte) para óxido nítrico (forte doador $-\sigma$ ) e este processo de transferência de elétrons seja seguido de uma reação de solvólise com liberação do fármaco e formação de um complexo de Ru(III) estável termicamente, Equação 25

$\mathrm{L}-\mathrm{Ru}^{\mathrm{II}}-\mathrm{NO}^{+} \rightarrow \mathrm{L}-\mathrm{Ru}^{\mathrm{III}}-\mathrm{NO}^{0} \stackrel{\text { solvente }}{\longrightarrow} \mathrm{Ru}^{\mathrm{III}}+\mathrm{NO}^{0}$

\section{Química e eletrônica molecular: moléculas atuando como fios moleculares eletrônicos}

As reações de transferência de elétrons a distâncias longas não estão restritas ao processos de conversão de energia solar ou ao meio biológico. A última década pode ser caracterizada pelo desenvolvimento de novos materiais com aplicações que variam dos dispositivos óticos eletrônicos à fotossíntese $\operatorname{artificial~}^{41-44}$. Estes estudos visam a síntese de compostos supramoleculares com características específicas que sejam capazes de reconhecer, estocar, processar e enviar informações mimetizando os sistemas naturais ${ }^{41-43}$.

Tendo como inspiração o meio biológico, os sistemas supramoleculares são construídos pela associação de duas ou mais moléculas com atuações definidas (receptor e substrato), unidas por forças intermoleculares ${ }^{43}$, formando sistemas altamente organizados e complexos. Estas interações moleculares cooperativas são a base dos processos de reconhecimento celular, reação, transporte e regulação que ocorrem na biologia. Tais processos podem ser observados, por exemplo, nas ligações do substrato a proteínas receptoras, nas reações enzimáticas, nas associações imunológicas antígeno-anticorpo ${ }^{43}$.

O interesse em novos materiais surgiu na década de 50 com o desenvolvimento da eletrônica e computação almejando a miniaturização dos componentes eletrônicos envolvidos. Um marco no desenvolvimento deste campo de pesquisa foi a descoberta da condução elétrica observada para uma molécula, por Aviram da IBM e Ratner da Universidade de New York, seguida mais recentemente pela observação de eletroquimiluminescência em polímeros conjugados ${ }^{44}$.

Considerando-se que a componente mais simples do circuito elétrico é o fio, o desenvolvimento dos fios moleculares vem sendo extensivamente pesquisado ${ }^{44,45}$.

Um fio molecular pode ser definido como sendo uma molécula longa, altamente conjugada na qual uma rede de insaturação (orbitais com simetria $\pi$ ) fornece o caminho para o movimento dos elétrons ${ }^{44}$. A preparação de estruturas orgânicas onde a conjugação estende-se por cerca de centenas de unidades monoméricas, tais como as obtidas nos tiofenos, pirróis ou acetilenos, resulta na comunicação e condução eletrônica tão eficiente quanto naquelas obtidas em condutores metálicos como o cobre $\left(10^{5} \mathrm{~S} \mathrm{~cm}^{-1}\right)$.

Combinando-se a fotoquímica inorgânica com polímeros condutores, é possível construir "fios moleculares" que façam a conexão de cromóforos e supressores dentro de uma única rede molecular. Para que isso seja possível, é preciso combinar uma série de características moleculares na mesma estrutura. Estas incluem absorção de luz, transferência de elétrons em uma única direção pela utilização de gradientes de energia livre e entrega de equivalentes, oxidativo e redutivo, produzidos fotoquimicamente ao sítio catalítico ${ }^{45}$. Estes requerimentos exigem um nível de complexidade molecular bastante alto.

Uma classe particularmente interessante de cromóforos para ser incorporada nestes polímeros condutores é os complexos polipiridínicos de $\mathrm{Ru}(\mathrm{II})$. Devido às suas propriedades fotofísicas, de oxidação e redução e de inércia fotoquímicas ${ }^{46}$ estes compostos vêm sendo extensivamente estudados como espécies receptoras de luz em dispositivos supramoleculares ${ }^{46}$.

Um exemplo ilustrativo envolve a reação de transferência de elétrons induzida fotoquimicamente do complexo [Ru(4,4'-dimetil2,2'-bipiridina $\left.)_{3}\right]^{2+}\left(\mathrm{E}_{0-0}=0,66 \mathrm{~V}\right.$ vs $\left.\mathrm{SCE}\right)$ para a polianilina ${ }^{47}, 2,5-$ dimetoxianilina, $\left(\mathrm{E}_{0-0}=+0,40 \mathrm{~V}\right.$ vs $\left.\mathrm{SCE}\right)$, Equação 26. Este processo resulta na conversão da forma básica da polianilina, PANb, para a forma condutiva $\mathrm{PAN}_{i}^{+}$.

$\mathrm{Ru}^{2+} \stackrel{\mathrm{luz}}{\longrightarrow} \mathrm{Ru}^{2+*}+\mathrm{PAN}_{\mathrm{b}} \rightarrow \mathrm{Ru}^{+}+\mathrm{PAN}_{\mathrm{i}}^{+}$

Uma outra estratégia empregada na construção controlada de polímeros condutores é a polimerização de olefinas cíclicas via metástase por abertura de anel (ROMP) ${ }^{48}$.

Devido à natureza viva do catalisador e sua tolerância a grupos funcionais, esta reação é particularmente interessante para a síntese de polímeros contendo unidades ativas fotoquimicamente e unidades ativas a reações redox ${ }^{48,49}$. Para estas aplicações, sistemas binucleares e multinucleares contendo complexos diiminas de Ru(II) são sintetizados em etapas ${ }^{50,51}$.

Recentemente, as propriedades fotoquímicas e fotofísicas do

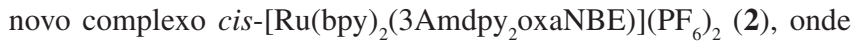
bpy $=2,2$ '-bipyridina e $3 \mathrm{Amdpy}_{2}$ oxaNBE é o ligante 5,6-bis(3amidopiridina)-7-oxanorborneno foram estudadas ${ }^{51}$ e comparadas a seus complexos precursores $c i s$ - $\left[\mathrm{Ru}(\mathrm{bpy})_{2}(3 \mathrm{Amnpy})_{2}\right]\left(\mathrm{PF}_{6}\right)_{2}$ (3) $\mathrm{e}\left[\mathrm{Ru}(\mathrm{bpy})_{3}\right]^{2+}$. No esquema reacional proposto ${ }^{51}$, Figura 4, o ligante 7-oxanorborneno (oxaNBE) foi ligado a duas moléculas de 3-aminopiridina (3Amnpy) formando a molécula $3 \mathrm{Amdpy}_{2} \mathrm{OxaNBE}$ e na sequiência coordenados ao núcleo de $\mathrm{Ru}(\mathrm{II})$-bipiridina. Os complexos 2 e 3 apresentam absorções intensas na região do visível entre 460-510 nm, atribuídas a uma superposição de absorções de caracterísiticas de MLCT $\left(\mathrm{d}_{\pi} \rightarrow\right.$ bpy e $\mathrm{d}_{\pi} \rightarrow \mathrm{L} ; \mathrm{L}=3 \mathrm{Amdpy}_{2}$ oxaNBE ou 3Amnpy). A introdução do ligante 7-oxanorborneno leva a alterações significativas nas propriedades fotoquímicas e fotofísicas destes complexos. Assim, apesar do complexo 3 ser fotoativo liberando o ligante 3-Amnpy quando excitado com luz visível, o complexo 2 apresenta luminescência intensa a $590 \mathrm{~nm}$ à temperatura ambiente em solução fluida, em filmes de glicose e à temperatura do $\mathrm{N}_{2}$ líquido. A emissão atribuída a uma transição de MLCT $(\mathrm{Ru} \rightarrow$ bpy) é caracterizada por um tempo de vida longo (650 ns em $\mathrm{CH}_{3} \mathrm{CN}$ e 509 ns em $\mathrm{H}_{2} \mathrm{O}$ ). Os estudos realizados da dependência do rendimento quântico de vida de emissão $\left(\phi_{\mathrm{em}}\right)$ com a temperatura foram avaliados pela equação $1 / \phi_{e m} k_{r}=k^{\prime} / k_{r}+k / k_{r} \exp \left(-E_{a} / R . T . k_{r}\right)$ onde, $\mathrm{k}_{\mathrm{r}}=$ constante de velocidade radiativa e $\mathrm{E}_{\mathrm{a}}=$ energia de ativação indicaram que as diferenças observadas nos processos fotoquímicos primários: complexo 3 (liberação da 3Amnpy) e com- 
plexo 2 (luminescência) ocorrem devido a um abaixamento de energia do estado excitado de menor energia MLCT indo de $\mathbf{3}$ para $\mathbf{2}$. A superfície de cruzamento calculada entre os estados excitados de MLCT/MC, $987 \mathrm{~cm}^{-1}$ é similar à observada para $\left[\mathrm{Ru}(\mathrm{bpy})_{3}\right]^{2+}$. A redução do ligante bpy no estado excitado de MLCT é indicada pelos espectros de absorção no estado excitado resolvidos no tempo, que mostram máximos de absorção a $400 \mathrm{~nm}$ característico do ligante bpy“. As propriedades fotocatalíticas de 2 foram espectroscopicamente demonstradas por supressão oxidativa dos estados excitados de MLCT usando as moléculas receptoras de elétrons metilviologêneo $(-0,45 \mathrm{mV})$ e o complexo $\left[\mathrm{Ru}\left(\mathrm{NH}_{3}\right)_{5} \mathrm{Cl}\right]^{+2}$.

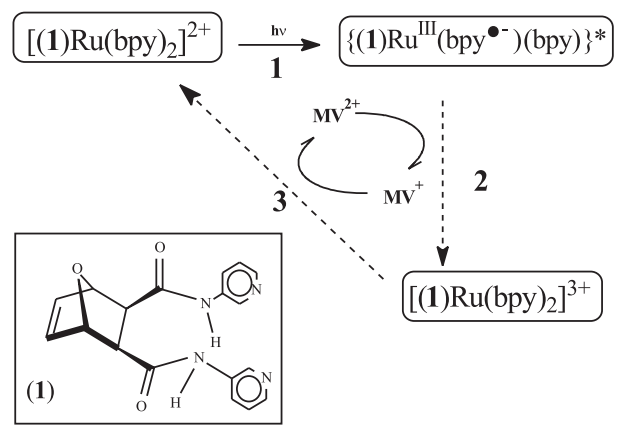

Figura 4. Esquema para a reação de transferência de elétrons fotoinduzida no complexo $\left[R u(\text { bpy })_{2}(3-\text { Apyoxa })\right]^{2+}$. Na etapa 1 , ocorre a transferência de elétron intramolecular do estado excitado do complexo $\left\{R u(b p y)_{2}\left(3 A m d p y_{2}\right.\right.$ oxaNBE $\left.)\right\} *$ excitado para o ligante bpy. Na etapa 2, um elétron é transferido do ligante bpy- reduzido para o receptor de elétrons externo metilviologêneo $\left(\mathrm{MV}^{2+}\right)$. A etapa 3 é a transferência de elétrons do $M V^{+}$para o centro de $R u^{3+}$, regenerando o complexo inicial. A estrutura da molécula 3Apyoxa está inserida na Figura

As oportunidades para separação de cargas fotoinduzidas obtidas pelo desenvolvimento de compostos que se comportam como blocos construtores são ilimitadas. Uma das maiores dificuldade em gerar um sistema com sucesso é a síntese desses materiais. Cada uma das funções representadas na molécula deve ser sintonizada independentemente por variações sintéticas. A separação de carga "ótima" depende da nossa habilidade para desenvolver e sintetizar sistemas que apresentem transferência de elétrons rápida nos estados excitados e transferência de elétrons lenta no estado fundamental, de forma que o processo redox no estado excitado seja eficiente.

\section{Química e eletrônica molecular: movimentos conforma- cionais induzidos pela luz}

Não só o transporte de elétrons, como o obtido nos fios moleculares, é de interesse mas também o estoque e processamento de informação são de importância tecnológica. Sistemas deste tipo incluem os processos de interconversão simples "Yes/No" também como moléculas que realizam operações lógicas ${ }^{52,53}$. Os estímulos externos que encaminham esses processos de interconversão são em geral mudanças de $\mathrm{pH}$, variação de potenciais redox e irradiação com luz UV-Visível.

A natureza, que é nossa fonte de inspiração, fornece exemplos claros destas transformações. Essa estratégia tem sido amplamente usada para controlar as geometrias e funções de biomoléculas, nos processos de visão, de materiais orgânicos e de complexos supramoleculares ${ }^{24,52-54}$.

Para os sistemas artificiais, os processos de interconversão podem ser alcançados explorando-se tanto os fótons como os elétrons, ambos levando a alterações (escrevendo) nos sistemas químicos e acompanhando (lendo) seus estados excitados. Em geral, os sistemas deste tipo são divididos naqueles que se baseiam em processos de fotoisomerização e naqueles relacionados aos processos de transferência de elétrons fotoinduzida. Vários compostos do tipo doador-ponte-receptor apresentam movimento conformacional em solventes não polares durante excitação. A irradiação desses compostos com luz visível leva à formação de um estado excitado, localizado na unidade receptora, o qual então decai para um estado com cargas separadas ${ }^{54}$. Nesse estado, as subunidades doadora e receptora carregam uma carga positiva e uma negativa e estão separadas no espaço. Por outro lado, as atrações eletrostáticas aproximam as subunidades fazendo com que a molécula se contorça, o que pode resultar na isomerização da molécula como um todo. $\mathrm{O}$ essencial para a observação deste movimento conformacional é a luminescência característica de uma das subunidades, exemplificando um sistema onde fótons são empregados tanto na obtenção de estímulo como no processamento de sinal.

A ligação $\mathrm{C}=\mathrm{C}$ em 1,2-bis-(4-piridil)etileno, um ligante do tipo estireno, pode adotar configurações cis- e trans-. Esta interconversão pode ser induzida pela excitação com luz ${ }^{55}$ UV. Desta maneira, as geometrias das moléculas incorporando um ou mais desse tipo de ligante podem ser alteradas reversivelmente, pela isomerização controlada dos sítios fotoativos. Como consequiência, tais alterações estruturais podem ser exploradas de forma a controlar as propriedades físico-químicas de tais moléculas e/ou do meio circunvizinho. Como exemplo, a coordenação desse ligante ao complexo luminescente $f a c$ - $\left[\operatorname{Re}(\mathrm{fen})(\mathrm{CO})_{3}(\mathrm{bpe})\right]^{+}$, onde fen = fenantrolina; bpe =1,2-bis(4-piridil)-etileno, desloca a isomerização trans- para cisdo ligante para o vermelho com emissão de luz amarela de natureza de MLCT característica do centro de $\operatorname{Re}(\mathrm{I})^{56}$. A reação de fotoisomerização reversa cis- para trans- resulta na supressão da luminescência.

Experimentos de fotólise relâmpago acompanhada por IV demonstraram que para o complexo com o ligante em posição trans, o estado excitado de menor energia está localizado sobre o ligante ${ }^{57}$. O esquema mostrado na Figura 5 ilustra as diferenças de energia dos estados excitados de MLCT e IL para os complexos de Re(I) com os ligantes cis- e trans- bpe.
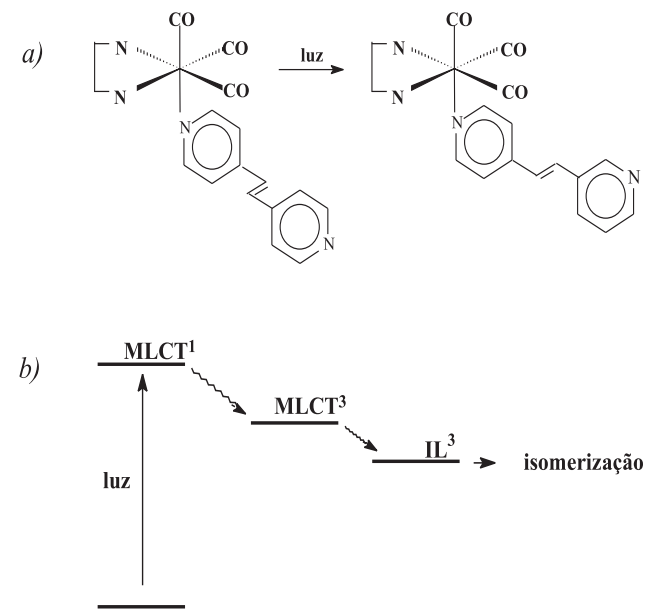

Figura 5. a) Reação de isomerização (trans- para cis-) induzida pela luz do ligante bpe = 1,2-bis(4-piridil)-etileno coordenado ao centro metálico de $\operatorname{Re}(\mathrm{I}) \mathrm{em}\left[\operatorname{Re}(\mathrm{CO})_{3}(\mathrm{fen})(\mathrm{trans}-\mathrm{bpe})\right]^{+}$. b) Diagram a de energia proposto para a reação de isomerização

Para o complexo $f a c$ - $\left[\operatorname{Re}(\mathrm{fen})(\mathrm{CO})_{3}(\text { cis-bpe })\right]^{+}$, o estado excitado de menor energia atribuído ao ligante bpe é deslocado para o azul em relação ao isômero trans-, fac-indicando uma maior con- 
tribuição dos estados excitados de MLCT em relação a IL, o que permite uma competição entre o decaimento radiativo de MLCT com o caminho não radiativo, IL do ligante.

Em contrapartida, em meio rígido a emissão no amarelo observada para $\mathrm{fac}$ - $\left[\operatorname{Re}(\mathrm{CO})_{3}(\mathrm{fen})(\text { cis-bpe })\right]^{+}$é totalmente suprimida no binuclear $\left[(\mathrm{fen})(\mathrm{CO})_{3} \operatorname{Re}(\text { cis-bpe }) \operatorname{Re}(\mathrm{CO})_{3}(\mathrm{fen})(\text { cis-bpe })\right]^{+}$, onde o estado excitado de menor energia está localizado sobre o ligante ${ }^{57}$. Como os autores enfatizam, a sintonia seletiva do estado emissor alcançada com a variação na mobilidade da molécula e rigidez do meio pode ser usada em sensores luminescentes e em dispositivos eletrônicos.

O sucesso operacional destas máquinas moleculares depende da escolha apropriada das unidades funcionais, de forma a se conseguir a integração correta das funções. Por exemplo, habilidade receptora, características redox, propriedades fotofísicas e sequiência correta de transferência de elétrons.

Como observado para os complexos Re(I)-estireno, os movimentos conformacionais podem ser engatilhados pela irradiação com luz visível e acompanhados por meio da absorção UV-vis e espectroscopia de luminescência.

\section{Fotodegradação de polímeros - ambiental}

Na última seção desta revisão, nós detalhamos os interesses e a aplicação da fotoquímica dos complexos de metais de transição no sentido de formação de polímeros estáveis e que apresentam propriedades específicas ao longo da cadeia. Uma outra frente da fotoquímica estuda polímeros que sejam reativos na presença de luz, ou seja, formação de polímeros fotodegradáveis ${ }^{58-60}$. O interesse nesses materiais vem da sua utilidade como plásticos fotodegradáveis, materiais biomédicos fotorresistivos e como precursores para materiais cerâmicos ${ }^{60}$.

Vários métodos são descritos na literatura para tornar materiais poliméricos fotoquimicamente degradáveis ${ }^{60}$. Eles se baseiam na incorporação de um cromóforo na cadeia polimérica. Os cromóforos mais comuns são as carbonilas, os cloretos metálicos ( $\left.\mathrm{LiCl}, \mathrm{FeCl}_{3}\right)$ e óxidos metálicos $\left(\mathrm{TiO}_{2}, \mathrm{ZnO}_{2}, \mathrm{CuO}\right)$ e alguns complexos metálicos como $\mathrm{M}(\mathrm{acac})_{\mathrm{n}}$ e $\mathrm{M}\left(\right.$ esterato $^{58}$. Nesses sistemas, a absorção de luz UV pelo cromóforo leva à quebra da cadeia polimérica e degradação do polímero ou à saída de um átomo de hidrogênio. A introdução de radicais na cadeia polimérica leva à degradação do polímero por um mecanismo de auto-oxidação, Equações 27 e 28.
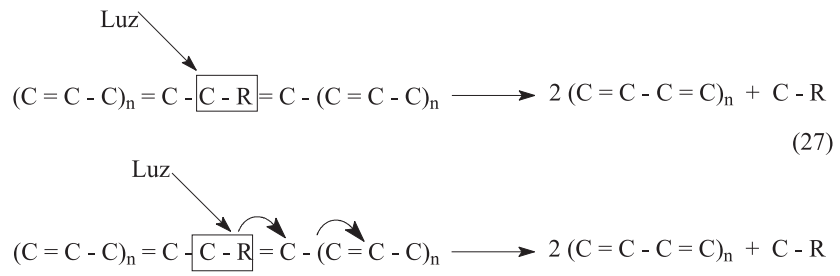

A fotooxidação de fenóis, aminoácidos e substratos aromáticos pelo par redox $\mathrm{Cu}^{\mathrm{II}} / \mathrm{Cu}^{\mathrm{I}}$ é um sistema bem caracterizado. A fotorredução de $\mathrm{Cu}^{\mathrm{II}}$ é acompanhada pela oxidação do ligante (substrato orgânico). $\mathrm{O}$ ciclo é completo pela presença de oxigênio, que reoxida o íon $\mathrm{Cu}^{\mathrm{I}}$ para $\mathrm{Cu}^{\mathrm{II}}$ com formação simultânea de superóxido e peróxido de hidrogênio.

Um outro método de fotodegradação de polímeros usando, no caso, luz visível envolve a síntese de polímeros com ligações M-M ao longo da cadeia polimérica. Esses polímeros são fotodegradáveis porque ocorre a quebra da ligação M-M quando irradiados com luz visível. As reações fotoquímicas dos polímeros em solução são similares às observadas para os complexos binucleares precursores. Apesar de esses sistemas não serem viáveis para aplicação industrial, são de interesse na avaliação dos fatores que controlam a velocidade dessas reações.

Muitos outros sistemas capazes de fotooxidar moléculas orgânicas podem ser encontrados no meio ambiente ou usados para a purificação da água.

Os polímeros fotodegradáveis vêm sendo usados em embalagens em geral, particularmente para embalar agrotóxicos. Eles são fotodegradáveis para materiais com baixo peso molecular pela luz perdendo sua forma, mas infelizmente não são totalmente biodegradáveis após fotólise. É esse, ainda, o maior problema para tais polímeros.

\section{CONCLUSÃO}

Esta revisão procurou mostrar o desenvolvimento histórico da fotoquímica inorgânica, situando o momento político mundial e as necessidades globais que direcionaram as pesquisas para aplicações práticas. Neste contexto, usamos como exemplo a aplicação na área tecnológica de conversão de energia solar em energia elétrica ou química procurando sempre a conexão com os processos naturais. Procuramos também demonstrar os avanços neste campo com aplicações práticas nas áreas de medicina, biologia, ambiental e ciências dos materiais. Muitas das pesquisas discutidas nesta revisão visam simular e modelar os diferentes processos biológicos usando a luz e os complexos de metais de transição. Estas investigações abrem perspectivas não só para a elucidação destes processos naturais mas, também, para o desenvolvimento de novas gerações de drogas mais seletivas e eficazes, bem como para o desenvolvimento de processos artificiais de aproveitamento da energia solar, estocagem e processamento de informações em nível molecular.

\section{REFERÊNCIAS}

1. Nazarov, E. K.; Nikitin, A. T.; Ponomarev-Stepnoy, N. N.; Protsenko, A. N.; Stolyarevskii, A. Ya.; Doroshenko, N. A.; Int. J. Hydrogen Energy 1990, 15, 4; Winter, C. J.; Int. J. Hydrogen Energy 2005, 30, 1371.

2. Mentus, S.; Mojovic, Z.; Cvjeticanin, N.; Tesic, Z.; J. New Mat. Electrochemical System 2004, 7, 213; Lipovestsky, V.; Int. J. Hydrogen Energy 2004, 29, 1555.

3. Iwasa, N.; Yoshikawa, M.; Nomura, W.; Arai, M.; Appl. Catal., A 2005, 292, 215.

4. Konigstein, C.; Bauer, R.; Int. J. Hydrogen Energy 1997, 22, 471.

5. Goetzberger, A.; Hebling, C.; Schock, H. W.; Mater. Sci. Eng., R 2003, 40, 1.

6. Smeastad, G. P.; Gratzel, M.; J. Chem. Educ. 1998, 75, 752; Bignozzi, C. A.; Argazzi, R.; Kleverlaan, C. J.; Chem. Soc. Rev. 2000, $29,87$.

7. Garcia, C. G.; Pólo, A. S.; Iha, N. Y. M.; J. Photochem. Photobiol., A 2003, 160, 87; Argazzi, R.; Iha, N. Y. M.; Zabri, H.; Odobel, F.; Bignozzi, C. A.; Coord. Chem. Rev. 2004, 248, 1299; Polo, A. S.; Itokazu, M. K.; Iha, N. Y. M.; Coord. Chem. Rev. 2004, 248, 1343.

8. Nazeeruddin, M. K.; Zakeeruddin, S. M.; Lagref, J. J-.; Liska, P.; Comte, P.; Barolo, C.; Viscardi, G.; Schenk, K.; Gratzel, M.; Coord. Chem. Rev. 2004, $248,1317$.

9. Brown, G. M.; Brunschwig, B. S.; Creutz, C.; Endicott, J. F.; Sutin, N.; J. Am. Chem. Soc. 1979, 101, 1298; Sutin, N.; Creutz, C.; Pure Appl. Chem. 1980, 52, 2717.

10. Amouyal, E.; Sol. Energy Mater. Sol. Cells 1995, 38, 249.

11. Lee, J. C.; Greenbaum, E.; J. Phys. Chem. B 2004, 108, 3935; Gust, D.; Moore, T. A.; Moore, A. L.; Acc. Chem. Res. 2001, 34, 40.

12. Howard, J. B.; Rees, D. C.; Chem. Rev. 1996, 7, 2965; Olson, J. M.; Blankenship, R. E.; Photosynth. Res. 2004, 80, 373; Sargent, P. J.; Farnaud, S.; Evans, R. W.; Curr. Med. Chem. 2005, 12, 2683.

13. Gray, H. B.; Winkler, J. R.; Quarterly Rev. Biophysics 2003, 36, 341; Di Donato, M.; Peluso, A.; Theor. Chem. Acc. 2004, 111, 303.

14. Kim, S. T.; Heelis, P. F.; Sancar, A.; Methods Enzymol. 1995, 258, 319; Proshlyakov, D. A.; Pressler, M. A.; DeMaso, C.; Leykam, J. F.; DeWitt, D. L.; Babcock, G. T.; Science 2000, 290, 1588. 
15. Davidson, V. L.; Acc. Chem. Res. 2000, 33, 87.

16. Matias, P. M.; Pereira, I. A. C.; Soares, C. M.; Carrondo, M. A.; Prog Biophys. Mol. Biol. 2005, 89, 292.

17. Bellelli, A.; Brunori, M.; Brzezinski, P.; Wilson, M. T.; Methods 2001, 24, 139; Millett, F.; Durham, B.; Biochemistry 2002, 41, 11315.

18. Winkler, J. R.; Nocera, D. G.; Yocom, K. M.; Bordignon, E.; Gray, H. B.; J. Am. Chem. Soc. 1982, 104, 5798; Nocera, D. G.; Winkler, J. R.; Yocom, K. M.; Bordignon, E.; Gray, H. B.; J. Am. Chem. Soc.1984, 106, 5145.

19. DiBilio, A. J.; Abu-Omar, M. M.; Carlos, R. M.; Crane, B. R.; Kiser, C. N.; Richards, J. H.; Sullivan, B. P.; Winkler, J. R.; Gray, H. B.; $13^{\text {th }}$ International Symposium on Photochemistry and Photophysics of Coordination Compounds, Isle of Lipari, Italia, 1999; DiBilio, A. J.; Crane, B. R.; Wehbi, W. A; Kyser, C. N.; Abu-Omar, M. M.; Carlos, R. M.; Richards, J. H.; Winkler, J. R.; Gray, H. B.; J. Am. Chem. Soc. 2001, 123, 3181.

20. Busby, M.; Gabrielsson, A.; Matousek, P.; Towrie, M.; Di Bilio, A. J.; Gray, H. B.; Vlcek, A.; Inorg. Chem. 2004, 43, 4994.

21. Hamachi, I.; Tanaka, S.; Tsukiji, S.; Shinkai, S.; Oishi, S.; J. Am. Chem. Soc. 1999, 121, 5500; Yavin, E.; Weiner, L.; Arad-Yellin, R.; Shanzer, A.; J. Phys. Chem. A 2004, 108, 9274 .

22. Zimmermann, M.; Fluck, J.; Thi, L. T. B.; Kolarik, C.; Kumpf, K.; Hofmann, M.; Curr. Top. Med. Chem. 2005, 5, 785.

23. Brancaleon, L.; Moseley, H.; Lasers Med. Sci. 2002, 17, 173.

24. Cembran, A.; Gonzalez-Luque, R.; Altoe, P.; Merchan, M.; Bernardi, F.; Olivucci, M.; Garavelli, M.; J. Phys. Chem. A 2005, 109, 6597.

25. Kruse, O.; Rupprecht, J.; Mussgnug, J. R.; Dismukes, G. C.; Hankamer, B.; Photochem. Photobiol. Sci. 2005, 4, 957.

26. Weichenthal, M., Schwarz, T.; Photodermatol. Photoimmunol. Photomed. 2005, 21, 260.

27. Lehmann, B.; Photochem. Photobiol. 2005, 295, 24; Cannon, J. B.; J. Pharm. Sci. 1993, 42, 435; Madan, A.; Acta Pediátrica 2005, 94, 1360.

28. Karu, T. I.; Pyatibrat, L. V.; Kolyakov, S. F.; Afanasyeva, N. I.; J. Photochem Photobiol., B 2005, 81, 98; Morimoto, Y.; Arai, T.; Kikuchi, M.; Nakajama, S.; Nakamura, H.; Lasers Surg. Med. 1994, 15, 191.

29. Hathaway, B. J. Em Comprehensive Coordination Chemistry; Wilkinson, G.; Gillard, R. D.; McCleverly J. A., eds.; Pergamon: Oxford, 1987, vol. 5, p. 534774.

30. Sternberg, E. D.; Dolphin, D.; Tetrahedron 1998, 54, 4151; Lang, K.; Mosinger, J.; Wagnerová, D. M.; Coord. Chem. Rev. 2004, 248, 321; Plaetzer, K.; Kiesslich, T.; Oberdanner, C. B.; Krammer, B.; Curr. Pharm. Des. 2005, 11, 1151.

31. Ortmans, I.; Moucheron, C.; Mesmaeker, K. A.; Coord. Chem. Rev. 1998, 168, 233; DeRosa, M. C.; Crutchley, R. J.; Coord. Chem. Rev. 2002, 233, 351; Clarke, M. J.; Coord. Chem. Rev. 2003, 236, 207.

32. Nonaca, M.; Ikeda, H.; Inokuchi, T.; Cancer Lett. 2002, 184, 171; Lottner, C.; Knuechel, R.; Bernhardt, G.; Brunner, H.; Cancer Lett. 2004, 203, 171; Kim, Y.-S.; Song, R.; Lee, C. O.; Sohn, Y. S.; Bioorg. Med. Chem. Lett. 2004, 14, 2889; DeRosa, F.; Bu, X. H.; Pohaku, K.; Ford, P. C.; Inorg. Chem. 2005, 44,4166

33. Megson, I. L.; Drugs Future 2000, 25, 701; Ignarro, L. J.; Curr. Top. Med. Chem. 2005, 5, 595; Ford, P. C.; Wecksler, S.; Coord. Chem. Rev. 2005, 249 , 217.

34. Stuehr, D. J.; Biochim. Biophys. Acta 1999, 1411, 217; Aktan, F.; Life Sci. 2004, 75, 639; Kendrick, K. M.; Guevara-Guzman, R.; Zorrilla, J.; Hinton, M. R.; Broad, K. D.; Mimmack, M.; Ohkura, S.; Nature 1997, 388, 670; Bode-Boger, S. M.; Eur. J. Clin. Pharm. 2006, 62, 91

35. Dorman, T.; Thompson, D. A.; Breslow, M. J.; Lipsett, P. A.; Rosenfeld, B. A. $\mathrm{J}$; Clin. Anesth. 2001, 13,16.

36. Oszajca, J.; Stochel, G.; Wasielewska, E.; Stasicka, Z.; Gryglewski, R. J.; Jakubowski, A.; Cieslik, K.; J. Inorg. Chem. Biochem. 1998, 69, 121.

37. Wolfe, S. K.; Swinehert, J. H.; Inorg. Chem. 1975, 14, 1049.

38. Cottrell, J. E.; Casthely, P.; Brodie, J. D.; Patel, K.; Klein, A.; N. Engl. J. Med. 1978, 298, 809; Zerbe, N.; Wagner, N. F.; Wagner, B. K. J.; Crit. Care Medicine 1993, 21,465 .

39. Carlos, R. M.; Ferro, A. A.; Silva, H. A. S.; Gomes, M. G.; Borges, M. M. M.; Ford, P. C.; Tfouni, E.; Franco, D. W.; Inorg. Chim. Acta 2004, 357, 1381;
Carlos, R. M.; Cardoso, D. R.; Castellano, E. E.; Osti, R. Z.; Camargo, A. J.; Macedo, L. G.; Franco, D. W.; J. Am. Chem. Soc. 2004, 126, 2546; de Lima, R. G.; Sauaia, M. G.; Bonaventura, D.; Tedesco, A. C.; Lopez, R. F. V.; Bendhack, L. M.; da Silva, R. S.; Inorg. Chim. Acta 2005, 358, 2643; Ford, P. C.; Wecksler, S.; Coord. Chem. Rev. 2005, 249, 1382; Bordini, J.; Ford, P. C.; Tfouni, E.; Chem. Commun. 2005, 33, 4169.

40. Rademaker-Lakhai, J. M.; van den Bongard, D.; Pluim, D.; Beijnen, J. H.; Schellens, J. H. M.; Clinical Cancer Res. 2004, 10, 3717; Duzenli, S.; Bakuridze, K.; Gepdiremen, A.; Toxicology in Vitro 2005, 19, 589.

41. Halls, J. J. M.; Walsh, C. A.; Greenham, N. C.; Marseglia, E. A.; Friend, R. H.; Moratti, S. C.; Holmes, A. B.; Nature 1995, 376, 498; James, D. K.; Tour, J. M.; Top. Curr. Chem. 2005, 257, 33.

42. Demas, J. N.; DeGraff, B. A.; Coord. Chem. Rev. 2001, 211, 317; Huynh, M H. V.; Dattelbaum, D. M.; Meyer, T. J.; Coord. Chem. Rev. 2005, 249, 457; Faxen, K.; Gilderson, G.; Adelroth, P.; Brzezinski, P.; Nature 2005, 437, 286.

43. Lehn, J. M.; Angew. Chem. Int. Ed. 1988, 27, 89; Balzani, V.; Scandola, F. Em Comprehensive Supramolecular Chemistry; Lehn, J. M.; Atwood, J. L.; Davies, J. E. D.; Macnicol, D. D.; Vogler, F., eds., Pergamon: Oxford, 1996, vol. 10, p. 687.

44. Aviram, A.; Ratner, M. A.; Chem. Phys. Lett. 1974, 29, 277; Burroughes, J. H.; Bradley, A. R.; Brown, A. R.; Marks, R. N.; MacKay, K.; Friend, R. H.; Burn, P. L.; Holmes, A. B.; Nature 1990, 347, 539.

45. Grinstaff, M. W.; Angew. Chem., Int. Ed. 1999, 38, 3629; Tagami, K.; Tsukada, M.; Matsumoto, T.; Kawai, T.; Phys. Rev. B: Condens. Matter Mater. Phys. 2003, 67, 245324.

46. Balzani, V.; Moggi, L.; Manfrin, M. F.; Bolletta, F.; Coord. Chem. Rev. 1975, 15, 321; Ioachim, E.; Medlycott, E. A.; Hanan, G. S.; Loiseau, F.; Campagna, S.; Inorg. Chim. Acta 2006, 359, 766.

47. Paul, E. W.; Ricco, A. J.; Wrighton, M. S.; J. Phys. Chem. 1985, 89, 1441

48. Grosshenny, V.; Harriman, A.; Hissler, M.; Ziessel, R.; J. Chem. Soc. Faraday Trans. 1996, 92, 2223.

49. Matos, J. M. E.; Batista, N. C.; Carvalho, R. M.; Santana, S. A. A.; Puzzi, P. N.; Sanches, M.; Lima-Neto, B. S.; Quim. Nova 2007, 30, 431.

50. Rezvani, A.; Bazzi, H. S.; Chen, B.; Rakotondradany, F.; Sleiman, H. F.; Inorg. Chem., 2004, 43, 5112; Bernechea, M.; Lugan, N.; Gil, B.; Lalinde, E.; Lavigne, G.; Organometallics 2006, 25, 684.

51. Inglez, D. S.; Lima, F. C. A.; Silva, A. B. F.; Simioni, A. R.; Tedesco, A. C.; Daniel, J. F. S.; Lima-Neto, B. S.; Carlos, R. M.; Inorg. Chem. 2007, 46, 5744.

52. Winnischofer, H.; Toma, H. E.; Araki, K.; J. Nanosci. Nanotechnol. 2006, 6 , 1701; Araki, K.; Toma, H. E.; Quim. Nova 2002, 25, 962; Toma, H. E.; J. Braz. Chem. Soc. 2003, 14, 845; Welter, S.; Brunner, K.; Hofstraat, J. W.; De Cola, L.; Nature 2003, 421, 54.

53. Tsivgoulis, G. M.; Lehn, J. M.; Angew. Chem., Int. Ed. 1995, 34, 1119; Ji, H. F.; Dabestani, R.; Brown, G. M.; J. Am. Chem. Soc. 2000, 122, 9306; Asanuma, H.; X-Liang, T.; Yoshida, A; Yamazawa, M.; Angew. Chem., Int. Ed. 2000, 39, 1316.

54. Lauteslager, X. Y.; van Stokkum, I. H. M.; van Ramesdonk, H. J.; Brouwer, A. M.; Verhoeven, J. W.; J. Phys. Chem. A 1999, 103, 653.

55. Wenger, O. S.; Henling, L. M.; Day, M. W.; Winkler, J. R.; Gray, H. B.; Inorg. Chem. 2004, 43, 2043

56. Itokazu, M. K.; Polo, A. S.; de Faria, D. L. A.; Bignozzi, C. A.; Iha, N. Y. M.; Inorg. Chim. Acta 2001, 313, 149.

57. Dattelbaum, D. M. ;Itokazu, M. K.; Iha, N. Y. M.; Meyer, T. J.; J. Phys. Chem A 2003, 107, 4092; Itokazu, M. K. ;Pólo, A. S.; Iha, N. Y. M.; J. Photochem. Photobiol., A 2003, 160, 27.

58. Tyler, D. R.; Chen, R.; Macromol. Symp. 2004, 209, 231; Tyler, D. R.; Coord. Chem. Rev. 2003, 246, 291; Shirai, M.; Suyama, K.; Okamura, H.; Tsunooka, M.; J. Photopolym. Sci. Technol. 2002, 15, 715.

59. West, R.; J. Organomet. Chem. 1986, 300, 327; Yajima, S.; Hayashi, J.; Omori, M.; Chem. Lett. 1975, 931

60. Grassie, N.; Scott, G.; Polymer Degradation and Stabilization, Cambridge University Press: New York, 1985; Hocking, P. J.; J. Macromol. Sci. Review in Macromolecular Chem. Phys. 1992, C32, 35; Tenhaeff, S. C.; Tyler, D. R.; Organometallics 1991, 10, 473; Tenhaeff, S. C.; Tyler, D. R.; Organometallics 1991, 10, 1116. 